\title{
STUDI DESKRIPTIF IMPLEMENTASI PROGAM IMUNISASI DASAR BAYI DALAM MEWUJUDKAN HAK KESEHATAN \& PERLINDUNGAN ANAK (DI PUSKESMAS KALIWUNGU KUDUS TAHUN 2021)
}

\author{
Intan Permata Dewi*1, Wahyu Widyaningsi ${ }^{2}$ \\ 1,2 Program Studi Ilmu Kebidanan, Politeknik Kudus, Indonesia \\ *e-mail: 1 Intan33_permata@yahoo.com
}

\begin{abstract}
ABSTRAK
Angka kematian bayi merupakan indikator yang digunakan untuk menentukan derajat kesehatan. Salah satu upaya Pemerintah dalam meningkatkan kesehatan dan mewujudkan perlindungan anak adalah melalui penyelenggaraan program imunisasi. Program penyelenggaraan imunisasi diatur dalam Permenkkes Nomor 42 Tahun 2013 tentang penyelenggaraan imunisasi. Program penyelenggaraan imunisasi menjadi tanggungjawab penuh Pemerintah melalui Dinas Kesehatan Kabupaten. Tujuan dalam penelitian ini adalah menjelaskan gambaran implementasi program pelayanan imunisasi dasar lengkap pada bayi. Metode dalam penelitian ini adalah kualitatif. Spesifikasi dalam penelitian ini adalah deskriptif analitik. Teknik sampling menggunakan purposive sampling. Hasil dalam penelitian ini diketahui dengan adanya penyelenggaraan imunisasi di Puskesmas Kaliwungu Kabupaten Kudus maka angka kesakitan bayi dan angka kematian bayi menurun sehingga hak kesehatan dan perlindungan anak dapat terwujud. Pemenuhan logistik dan jenis imunisasi sudah sesuai dengan ketentuan. Dalam hal teknis terdapat adanya pengelolaan sumber daya manusia yang tumpah tindih, dimana penyelenggaraan imunisasi menjadi tanggungjawab bidan. Sedangkan sesuai dengan Permenkes Nomor 42 Tahun 2013 tentang penyelenggaraan imunisasi bahwa penyelenggaraan imunisasi menjadi tanggungjawab Tim pengelolaan imunisasi.Meskipun terdapat beberapa hal yang belum sesuai dengan ketentuan, secara umum penyelenggaraan imunisasi di Puskesmas Kaliwungu telah berjalan dengan baik. Hal ini dikarenakan terdapat beberapa faktor yang mendukung seperti tersedianya kebutuhan logistik dan faktor yang menghambat yakni penugasan yang belum sesuai dengan ketentuan.
\end{abstract}

Kata kunci: Program Imunisasi, Hak kesehatan dan perlindungan anak, Puskesmas Kaliwungu

\begin{abstract}
The infant mortality rate is an indicator used to determine health status. One of the Government's efforts in improving health and realizing child protection is through the implementation of an immunization program. The immunization program is regulated in the Minister of Health Regulation Number 42 of 2013 concerning the administration of immunization. The immunization program is the full responsibility of the Government through the District Health Office. The purpose of this study is to describe the implementation of a complete basic immunization service program for infants. The method in this research is qualitative. The specifications in this study are descriptive analytic. The sampling technique used purposive sampling. The results in this study are known by the implementation of immunization at the Kaliwungu Health Center, Kudus Regency, the infant morbidity rate and infant mortality rate decreases so that the right to health and child protection can be realized. Fulfillment of logistics and types of immunization are in accordance with the provisions. In technical terms, there is overlapping human resource management, where the administration of immunization is the responsibility of the midwife. Meanwhile, in accordance with the Minister of Health Regulation Number 42 of 2013 concerning the administration of immunization, the administration of immunization is the responsibility of the immunization management team. Although there are some things that are not in accordance with the provisions, in general the implementation of immunization at the Puskesmas Kaliwungu has been going well. This is because there are several supporting factors such as the availability of logistical needs and inhibiting factors, namely assignments that are not in accordance with the provisions.
\end{abstract}

Keywords: Immunization Program, Health rights and child protection, Kaliwungu Health Center 


\section{PENDAHULUAN}

Pembangunan nasional jangka panjang menitikberatkan pada sumber daya manusia yang berkualitas. Untuk itu generasi muda yang dewasa ini memerlukan asuhan dan perlindungan terhadap penyakit. Perlindungan terhadap penyakit dapat menghambat tumbuh kembangnya menuju masa dewasa yang berkualitas.Indonesia masih memiliki angka kesakitan bayi yang cukup tinggi. Angka kesakitan bayi yang tinggi dapat dipengaruhi oleh beberapa hal antara lain status gizi, jaminan pelayanan kesehatan anak, perlindungan kesehatan anak, faktor sosial ekonomi dan pendidikan ibu. Anak mempunyai hak untuk hidup sehat. Anak mempunyai hak untuk diberikan pelayanan kesehatan yang berkualitas [1]. Anak memperoleh hak untuk mendapatkan kesejahteraan dengan memperoleh fasilitas pelayanan kesehatan yang baik. Anak memperoleh hak untuk dilindungi yang artinya dilindungi dari sebuah wabah penyakit ataupun infeksi dengan cara pelayanan kesehatan secara preventif atau pencegahan terhadap terjadinya suatu penyakit.

Kesehatan merupakan indikator pembangunan bangsa. Salah satu indikator derajat kesehatan di Indonesia adalah penurunan angka kematian ibu dan bayi. Dalam hal ini angka kematian bayi masih menjadi kewajiban pemerintah agar semua bayi diberikan perawatan yang intensif karena bayi sangat rentan terjadi suatu iinfeksi dan penyakit. Kesehatan adalah elemen terpenting dalam kehidupan yang sangat dibutuhkan oleh manusia. Sesuai dengan isi dari UU Kesehatan Nomor 36 Tahun 2009 pasal 4 yang berbunyi "setiap orang berhak atas kesehatan". Kesehatan merupakan hak bagi setiap manusia termasuk hak anak untuk mendapatkan pelayanan kesehatan, salah satunya adalah pelayanan imunisasi [2].

Hak Asasi Manusia merupakan suatu hak dasar yang dibawa sejak lahir yang berlaku universal pada semua manusia. Menurut UU Nomor 39 Tahun 1999, Hak Asasi Manusia adalah seperangkat hak yang melekat pada hakikat dan keberadaan manusia sebagai makhluk Tuhan Yang Maha Esa dan merupakan anugerah-Nya yang wajib dihormati, dijunjung tinggi dan dilindungi oleh negara, hukum, Pemerintah, dan setiap orang demi kehormatan serta perlindungan harkat dan martabat manusia [3]. Perlindungan anak adalah segala bentuk kegiatan untuk menjamin dan melindungi anak dan hak- haknya agar dapat hidup, tumbuh dan berkembang, dan berpartisipasi secara optimal sesuai dengan harkat dan martabat kemanusiaan, serta mendapat perlindungan dari kekerasan dan diskriminasi. Dalam Undang-Undang Nomor 35 Tahun 2014 tentang perlindungan anak, Pemerintah daerah berkewajiban dan bertanggungjawab untuk melaksanakan dan mendukung Kebijakan Nasional dalam penyelenggaraan perlindungan anak di Daerah, salah satunya dengan menyelenggarakan program imunisasi di Puskesmas [4]. Menurut Peraturan Menteri Kesehatan Nomor 75 Tahun 2014 tentang Puskesmas, Puskesmas adalah fasilitas pelayanan kesehatan yang menyelenggarakan upaya kesehatan masyarakat dan upaya kesehatan perseorangan tingkat pertama, dengan lebih mengutamakan upaya promotif dan preventif, untuk mencapai derajat kesehatan masyarakat yang setinggi-tingginya di wilayah kerjanya [5].

Kesehatan anak merupakan investasi bagi negara dan anak yang sehat mencerminkan derajat kesehatan bangsa. Anak merupakan generasi penerus bangsa yang diharapkan dan dapat meningkatkan pembangunan bangsa yang lebih baik. Masalah kesehatan anak merupakan masalah yang utama di bidang kesehatan. Tingginya Angka Kematian Bayi disebabkan oleh beberapa penyakit diantaranya adalah tetanus $18 \%$, difteri $80 \%$, hepatitis $16 \%$, radang selaput otak $70 \%$, radang paru-paru $28 \%$ dan campak 21\%. Masalah kesehatan bayi tersebut bersumber dari infeksi yang merupakan penyakit dapat dicegah dengan imunisasi Hb, BCG, DPT, Polio dan Campak.

Program imunisasi merupakan salah satu upaya untuk memberikan perlindungan kepada penduduk terhadap penyakit tertentu. Program imunisasi diberikan kepada populasi yang dianggap rentan terjangkit penyakit menular, yaitu bayi, balita, anak-anak, wanita usia subur, dan ibu hamil. Pelaksanaan imunisasi di puskesmas merupakan unsur yang sangat penting dalam pelayanan imunisasi, mereka mempunyai tanggung jawab yang besar dalam keberhasilan program imunisasi yaitu tercapainya UCI secara merata di tingkat desa [6]. 
Imunisasi telah terbukti sebagai salah satu upaya kesehatan masyarakat yang sangat penting. Bayi perlu diberi imunisasi dasar lengkap sejak lahir yang dimulai dengan memberikan imunisasi hepatitis B untuk terhindar dari penyakit hepatitis B. Imunisasi dasar lengkap dapat melindungi bayi dari berbagai penyakit. Apabila tidak dicegah penyakit berbahaya tersebut dapat menyebabkan komplikasi dengan resiko kematian. Selain itu penyakit tersebut berpotensi menimbulkan wabah yang berdampak besar bagi masyarakat di sekitarnya dan pastinya membutuhkan biaya sangat besar untuk pemberantasannya. Melihat tingginya angka kematian bayi dan angka kesakitan bayi di Indonesia yang disebabkan oleh infeksi. Dalam hal ini pemerintah membuat kebijakan untuk menangani persoalan dengan cara pemberian imunisasi. Sehingga pemerintah mengeluarkan kebijakan dengan mengundangkan Permenkes Nomor 42 Tahun 2013 tentang Penyelenggaraan Imunisasi. Imunisasi dasar lengkap sangat penting diberikan pada bayi yang berusia $0-11$ bulan untuk memberikan kekebalan dari penyakit yang dapat dicegah dengan imunisasi (PD3I) [7]. Kekebalan yang dapat diberikan sepertikekebalan terhadap penyakit tuberkulosis, difteri, pertusis, tetanus, polio, hepatitis B, dan Campak. Pada masa awal kehidupan, bayi sangat rentan terkena penyakit tersebut. Apabila bayi terkena penyakit tersebut maka akan menyebabkan derita fisik, mental, kecacatan, dan menimbulkan kematian. Imunisasi dasar lengkap dilakukan agar bayi dapat tetap tumbuh dan berkembang secara optimal dalam keadaan sehat. Agar PD3I dapat tercapai, maka cakupan imunisasi dasar lengkap harus dipertahankan dan dilakukan secara merata.

Imunisasi dasar lengkap telah menunjukkan keberhasilan dan merupakan usaha yang sangat hemat biaya dalam mencegah penyakit menular. Imunisasi juga telah berhasil menyelamatkan begitu banyak kehidupan dibandingkan dengan upaya kesehatan masyarakat lainnya. Upaya imunisasi saat ini menjadi program pengembangan imunisasi dalam rangka pencegahan penularan penyakit yang dapat dicegah dengan imunisasi dasar lengkap. Vaksin yang dapat digunakan dalam pencegahan penyakit telah banyak beredar di Indonesia. Hasil daya lindung yang ditimbulkannya juga telah terbukti bermanfaat. Sebagai salah satu contoh adalah keberhasilan dunia termasuk Indonesia dalam memberikan imunisasi campak yang dapat menghilangkan penyakit cacar. Sehubungan dengan hal tersebut, salah satu upaya yang dilakukan Pemerintah adalah penyelenggaraan imunisasi dasar lengkap sebagai wujud pemenuhan hak anak dan hak dalam perlindungan anak terhadap pelayanan kesehatan. Sehingga harapannya angka kematian bayi dan angka kesakitan bayi menurun dengan adanya pelaksanaan penyelenggaraan imunisasi dasar lengkap.

\section{BAHAN DAN METODE}

Metode dalam penelitian ini adalah kualitatif. Spesifikasi dalam penelitian ini adalah deskriptif analitik. Teknik sampling menggunakan purposive sampling. Dalam penelitian ini menggambarkan implementasi program pelayanan imunisasi dasar lengkap pada bayi dalam mewujudkan hak kesehatan dan perlindungan anak di Puskesmas Kaliwungu Kabupaten Kudus Tahun 2021. Sampel dalam penelitian ini adalah bidan pelaksana pelayanan imunisasi di Puskesmas Kaliwungu Kudus sebanyak 5 responden.

\section{HASIL DAN PEMBAHASAN}

Hasil dalam penelitian ini menggunakan metode deskriptif kualitatif pada lima responden didapatkan hasil kebutuhan vaksin di Puskesmas Kaliwungu di fasilitasi oleh Pemerintah dengan prosedur pemegang program imunisasi di Puskesmas membuat laporan vaksin kepada Dinas Kesehatan Kabupaten. Dinas kesehatan akan memenuhi kebutuhan vaksin sesuai kebutuhannya. Imunisasi dasar lengkap merupakan imunisasi yang diwajibkan oleh Pemerintah. Puskesmas merupakan tempat fasilitas pelayanan kesehatan yang harus menjalankan dari program yang ditentukan oleh Pemerintah seperti halnya imunisasi. Di Puskesmas Kaliwungu, jenis imunisasi dasar yang diberikan kepada anak usia 0 sampai dengan usia 9 bulan adalah Hepatitis B, Bacillus Calmette Guerin (BCG), Diphtheria Pertusis Tetanus-Hepatitis B (DPT-HB), Polio dan campak.

Jenis imunisasi wajib yang diberikan yaitu Hepatitis B0 untuk usia 0 bulan biasanya diberikan saat bayi lahir, BCG dan polio 1 untuk usia 1 bulan, DPT-HB 1 dan polio 2 untuk usia 
2 bulan, DPT-HB 2 dan polio 3 untuk usia 3 bulan, DPT-HB 3 dan polio 4 untuk usia 4 bulan dan yang terakhir campak untuk usia 9 bulan. Imunisasi hepatitis B diberikan pada saat segera setelah bayi lahir secara intramuskuler di lengan dengan dosis $0,5 \mathrm{cc}$, imunisasi Bacillus Calmette Guerin (BCG) diberikan pada saat bayi usia 1 bulan secara intarakutan di lengan kanan dengan dosis 0,05 cc, imunisasi Diphtheria Pertusis Tetanus-Hepatitis B (DPT-HB), diberikan selama 3 kali dan bersamaan dengan polio yang diberikan pada saat bayi usia 2 sampai dengan 3 bulan diberikan secara intramuskular dengan dosis $0,05 \mathrm{cc}$, imunisasi polio diberikan selama 4 kali pada saat bayi usia 1 sampai dengan 4 bulan dengan cara meneteskan vaksin polio 2 tetes kedalam mulut bayi, imunisasi campak diberikan secara subkutan di lengan atas bagian kiri dengan dosis $0,5 \mathrm{cc}$.

Pelayanan imunisasi diposyandu bidan desa mempunyai tanggungjawab penuh di posyandu tersebut yang dibantu oleh kader sebanyak 2 orang yang bertugas untuk mempromosikan, membujuk masyarakat agar mau datang ke posyandu untuk mengimunisasikan bayinya dengan cara memberikan informasi tentang pentingnya imunisasi, sebelumnya bidan bertugas memberikan pembinaan terhadap kader tentang proses pelayanan imunisasi sehingga kader bisa membantu dalam hal pencatatan imunisasi.Kebutuhan dalam penyelenggaraan imunisasi di Puskesmas Kaliwungu menjadi tanggungjawab pemerintah. Kebutuhan logistik terdiri dari Vaksin, Auto Disable Syringe, safety box. Penyimpanan vaksin di tempat khusus atau kulkas vaksin yang temperaturnya 20C - 80C. Dalam hal pelayanan imunisasi menjadi tanggung jawab penuh bidan.

Pelaksanaan pelayanan imunisasi dengan cara bidan memberikan informasi tentang imunisasi yang diberikan kemudian dilakukan penyuntikan sesuai dengan vaksin dan jadwal pemberian yang diberikan, pencatatan pelayanan imunisasi dilakukan di buku kohort. Pencatatan imunisasi di posyandu di buat di buku kuning/kohort bayi. Pencacatan dan pelaporan pelayanan imunisasi di puskesmas meliputi hasil cakupan imunisasi dengan cara hasil kegiatan imunisasi dilapangan dicatat di buku kuning. Peran serta masyarakat sangat bagus. Sumber daya manusia yang memberikan imunisasi juga sudah mengikuti pelatihan. Faktor yang menghambat terkadang pasien datang diluar jadwal imunisasi yang ditentukan, serta manajemen penugasan dimana imunisasi menjadi tanggungjawab penuh bidan.Faktor yang mendukung dalam penyelenggaraan imunisasi adalah kebutuhan logistik yang telah di fasilitasi oleh Dinas Kesehatan Kabupaten Kudus. Semua orang mempunyai hak untuk memperoleh pelayanan kesehatan. Salah satu pelayanan kesehatan antara lain penyelenggaraan imunisasi dasar lengkap. Penyelenggaraan imunisasi merupakan salah satu upaya pemerintah dalam mewujudkan kesehatan anak dalam pencegahan penyakit menular. Pelayanan imunisasi dilaksanakan di Dinas Kesehatan Kabupaten Kudus. Salah satunya di Puskesmas Kaliwungu.

Penyelenggaraan imunisasi dilakukan mulai perencanaan, pelaksanaan dan evaluasi. Perencanaan pelayanan imunisasi seperti kebutuhan logistik meliputi kebutuhan vaksin, Auto Disable Syringe dan safety box. Pelaksanaan penyelenggaraan imunisasi di Puskesmas Kaliwungu terdiri dari jenis imunisasi, tempat pelayanaan imunisasi dasar lengkap, petugas pelayanan imunisasi. Tempat pelayanan imunisasi dasar lengkap di Puskesmas Kaliwungu dilaksanakan secara massal di posyandu. Bidan sebagai petugas pelaksana pelayanan imunisasi bertanggugjawab mengumpulkan limbah ke dalam safety box, kemudian di bawa ke Puskesmas. Dari hasil penelitian di Puskesmas Kaliwungu pelaksana imunisasi dasar lengkap hanya dilakukan oleh satu bidan desa yang menjadi tanggung jawab di desa tersebut dengan dibantu oleh tim pembina desa atau yang biasa disebut dengan kader.

Berdasarkan uraian di atas dapat diketahui bahwa pelaksanaan pelayanan imunisasi di Puskesmas Kaliwungu ada hal yang sesuai dan belum sesuai dengan ketentuan Permenkes tentang pelayanan imunisasi. Hal yang sesuai adalah imunisasi dasar lengkap, tempat pelayanan imunisasi dan pengelolaan limbah. Hal yang tidak sesuai adalah petugas pelayanan imunisasi. Menurut hasil wawancara ketidaksesuaian tersebut dikarenakan keterbatasan tenaga. Namun dari hasil analisa dalam hal pembagian tugas terjadi ketidakseimbangan yang mengakibatkan pelayanan imunisasi di Puskesmas Kaliwungu belum maksimal. Ketidakseimbangan tersebut dapat dilihat dari dokter lebih mengutamakan pelayanan pengobatan umum di Puskesmas. Pelayanan imunisasi hanya dibebankan secara individu kepada bidan yang bertugas di poliklinik kesehatan desa. 
Pelaksana pelayanan imunisasi yang dimaksud dalam Peraturan Menteri Kesehatan Nomor 42 Tahun 2013 tentang penyelenggaraan imunisasi adalah tenaga kesehatan yang melaksanakan pelayananan imunisasi [7]. Dalam Permenkes tentang penyelenggaraan imunisasi dijelaskan bahwa pelaksana pelayanan imunisasi adalah dokter, dokter spesialis dan bidan di puskesmas. Sedangkan apabila dokter mendapatkan tugas yang lain dapat mendelegasikan kewenangan pelayanan imunisasi kepada bidan dan perawat sesuai ketentuan peraturan perundang-undangan untuk melaksanakan imunisasi dasar lengkap sesuai program Pemerintah.

Imunisasi merupakan tindakan pencegahan dan perlindungan terhadap penyakit yang paling baik pada anak. Anak memiliki hak memperoleh pelayanan kesehatan dan hak perlindungan anak. Pentingnya imunisasi menjadi kewajiban Pemerintah dan Pemerintah Daerah melalui Dinas Kesehatan Kabupaten untuk memberikan pelayanan imunisasi kepada anak sebagai wujud pemenuhan hak atas kesehatan anak dan hak atas perlindungan anak. Seperti halnya di Puskesmas Kaliwungu yang merupakan tempat fasilitas pelayanan kesehatan dibawah Dinas Kesehatan Kabupaten Kudus mempunyai tujuan untuk menjadikan warga hidup sehat, salah satu hal yang dilakukan dengan upaya preventif dengan cara pemberian imunisasi dasar lengkap pada anak yang dilakukan di masing-masing posyandu.

Salah satu wujud nyata yang dilakukan di Puskesmas Kaliwungu dalam memberikan pelayanan kesehatan preventif yaitu dengan penyelenggaraan imunisasi. Penyelenggaraan imunisasi di Puskesmas Kaliwungu meliputi perencanaan, pelaksanaan pelayanan imunisasi, monitoring dan evaluasi.

Berdasarkan hasil penelitian di Puskesmas Kaliwungu terdapat faktor pendukung penyelenggaraan imunisasi di Puskesmas Kaliwungu terdiri dari tersedianya kebutuhan logistik dan keamanan menjaga kualitas vaksin. Keamanan vaksin merupakan faktor pendukung dalam penyelenggraan imunisasi. Vaksin di Puskesmas Kaliwungu dikelola dengan baik dalam penyimpanannya. Keamanan vaksin merupakan salah satu hak pasien dalam pelayanan kesehatan. Hak pasien yang dalam hal ini adalah hak anak untuk diberikan pelayanan kesehatan yang aman. Pengelolaan vaksin yang tepat sampai dengan diberikan kepada anak dapat meningkatkan efektifitas kerja vaksin dalam pencegahan penyakit. Sehingga dapat mewujudkan hak kesehatan dan perlindungan anak secara optimal.

Pelaksanaan penyelenggaraan imunisasi di Puskesmas Kaliwungu terdiri dari jenis imunisasi, tempat pelayanaan imunisasi dasar lengkap, petugas pelayanan imunisasi, dan pengelolaan limbah. Hasil penelitian yang dilakukan di Puskesmas Kaliwungu jenis imunisasi dasar adalah Hepatitis B, Bacillus Calmette Guerin (BCG), Diphtheria Pertusis Tetanus-Hepatitis B (DPT-HB), Polio dan campak. Pelaksanaan di Puskesmas Kaliwungu imunisasi hepatitis B diberikan pada saat segera setelah bayi lahir secara intramuskuler di lengan dengan dosis $0,5 \mathrm{cc}$, imunisasi Bacillus Calmette Guerin (BCG), diberikan pada saat bayi usia 1 bulan secara intarakutan di lengan kanan dengan dosis $0,05 \mathrm{cc}$, imunisasi Diphtheria Pertusis Tetanus-Hepatitis B (DPT-HB), diberikan selama 3 kali dan bersamaan dengan polio yang diberikan pada saat bayi usia 2 sampai dengan 3 bulan diberikan secara intramuskular dengan dosis $0,05 \mathrm{cc}$, imunisasi polio diberikan selama 4 kali pada saat bayi usia 1 sampai dengan 4 bulan dengan cara meneteskan vaksin polio 2 tetes kedalam mulut bayi, imunisasi campak diberikan secara subkutan di lengan atas bagian kiri dengan dosis $0,5 \mathrm{cc}$.

Tempat pelayanan imunisasi dasar lengkap di Puskesmas Kaliwungu dilaksanakan secara massal di posyandu. Dalam hal pengelolaan limbah, bidan sebagai petugas pelaksana pelayanan imunisasi bertanggugjawab mengumpulkan limbah ke dalam safety box, kemudian di bawa ke Puskesmas. Dari hasil penelitian di Puskesmas Kaliwungu pelaksana imunisasi dasar lengkap hanya dilakukan oleh satu bidan desa yang menjadi tanggung jawab di desa tersebut dengan dibantu oleh tim pembina desa atau yang biasa disebut dengan kader.

Monitoring dan evaluasi penyelengaraan imunisasi di Puskesmas Kaliwungu terdiri dari pencatatan dan pelaporan serta pemantauan dan penanggulangan KIPI. Dalam hal pencatatan dan pelaporan penyelengaraan imunisasi bidan wajib melaporkan pelayanan imunisasi setiap akhir bulan. Dari hasil penelitian di Puskesmas Kaliwungu pencatatan hasil imunisasi untuk bayi dibuat oleh bidan desa masing-masing di buku kuning/kohort bayi. Hasil pencatatan dari masing-masing

JIGK Vol. 3, No. 02, Agustus 2021: 37 - 44 
bidan desa dilaporkan kepada bidan koordinator. Kemudian direkap di buku pencatatan imunisasi puskesmas dan dibuat laporan pencatatan imunisasi perbulan. Pencatatan dan pelaporan pelayanan imunisasi di Puskesmas Kaliwungu meliputi hasil cakupan imunisasi, pencatatan sasaran nama bayi, orang tua, tanggal lahir, jenis imunisasi yang diberikan, pencatatan keluar masuknya vaksi, pencatatan tanggal kadaluwarsa, pencatatatan penerimaan dan pengeluaran vaksin.

Monitoring kebutuhan logistik di Puskesmas Kaliwungu dilakukan setiap akhir bulan. Bidan koordinator melakukan monitoring administrasi dan fisik vaksin dalam pemberian imunisasi. Hasil monitoring dicatat kemudian dilaporkan secara bersamaan dengan laporan cakupan imunisasi. Dari hasil penelitian yang dilakukan di Puskesmas Kaliwungu pemantauan KIPI dilakukan setelah pemberian imunisasi. Apabila kader menemukan kasus KIPI segera menghubungi bidan pelaksana imunisasi. Penanganan KIPI di Puskesmas Kaliwungu dengan cara setiap KIPI yang dilaporkan oleh kader di observasi dan di catat oleh bidan pelaksana imunisasi. Bidan pelaksana melaporkan kepada bidan koordinator dan kepala Puskesmas. Bidan pelaksana melakukan observasi untuk mengetahui penyebabnya. KIPI yang memerlukan perawatan diobservasi di Puskesmas Kaliwungu untuk mendapatkan perawatan secara intensif. Pencatatan bidan pada kasus KIPI meliputi identitas anak, jenis vaksin yang diberikan, dosis, waktu pemberian vaksin, siapa yang memberikan, riwayat KIPI pada imunisasi terdahulu dan gejala klinis yang timbul. Monitoring dan evaluasi di Puskesmas Kaliwungu ada hal yang sesuai dan ada hal yang tidak sesuai dengan Permenkes tentang penyelenggaraan imunisasi. Hal yang sesuai adalah pencatatan dan pelaporan imunisasi. Hal yang belum sesuai adalah pemantauan dan penanggulangan KIPI.

Dalam Permenkes tentang penyelenggaraan imunisasi tentang pemantauan dan penanggulangan KIPI telah disebutkan bahwa apabila ada kejadian kasus KIPI, pemantauan KIPI dilakukan oleh supervisor tingkat Puskesmas. Supervisor tersebut melakukan observasi dan melengkapi laporan kronologis KIPI. Namun realisasi di Puskesmas Kaliwungu pemantauan KIPI dan pelaporan kronologis kejadian KIPI dilakukan oleh bidan pelaksana pelayanan imunisasi. Kemudian dilaporkan kepada bidan koordinator dan kepala Puskesmas. Hal ini terjadi karena manajemen penugasan, dimana tidak ada tenaga kesehatan yang ditugaskan untuk menjadi surveilans KIPI dalam penyelenggaraan imunisasi.

Faktor yang menjadi penghambat dalam penyelenggaraan imunisasi di Puskesmas Kaliwungu adalah pelaksana pelayanan imunisasi. Hal itu disebabkan karena ketidakseimbangan dalam penugasan di Puskesmas Kaliwungu Petugas pelaksana pelayanan imunisasi yang seharusnya dilakukan oleh tiga orang yakni hanya dilakukan oleh satu orang koordinator imunisasi.

Penyelenggaraan imunisasi merupakan wujud pemerintah dalam memenuhi hak anak, salah satunya untuk mewujudkan kesehatan dan perlindungan anak. Anak mempunyai hak untuk hidup sehat dan dilindungi dari penyakit menular yang dapat dicegah melalui pemberian imunisasi. Hak anak yang salah satunya adalah hak atas kesehatan anak menjadi tanggungjawab Pemerintah. Anak mempunyai hak atas pelayanan kesehatan meliputi pencegahan penyakit, penyembuhan penyakit pemulihan kesehatan, tercukupi kebutuhan gizi dan pengurangan angka kematian bayi. Dalam penyelenggaraan kesehatan pada anak, Pemerintah mempunyai upaya pembangunan kesehatan dan perlindungan untuk pencegahan penyakit pada anak. Upaya pembangunan yang menyeluruh, terpadu dan berkesinambungan yang mencakup upaya promotif (peningkatan), preventif (pencegahan), kuratif (penyembuhan) dan rehabilitatif (pemulihan). Upaya preventif yang dilakukan adalah dengan adanya penyelenggraan imunisasi untuk mewujukan kesehatan anak dan mencegah terjadinya penyakit menular tertentu pada anak. Dalam upaya penyelenggaraan imunisasi Pemerintah harus menjamin dan bertindak dalam beberapa hal meliputi ketersediaan kebutuhan logistik imunisasi yang aman, bermutu, efektif, terjangkau dan merata bagi masyarakat.

Imunisasi merupakan tindakan pencegahan dan perlindungan terhadap penyakit yang paling baik pada anak. Anak memiliki hak memperoleh pelayanan kesehatan. Pentingnya imunisasi menjadi kewajiban Pemerintah dan Pemerintah Daerah melalui Dinas Kesehatan 
Kabupaten untuk memberikan pelayanan imunisasi kepada anak sebagai wujud pemenuhan hak atas kesehatan anak. Seperti halnya di Puskesmas Kaliwungu yang merupakan tempat fasilitas pelayanan kesehatan dibawah Dinas Kesehatan Kabupaten Kudus mempunyai tujuan untuk menjadikan warga kecamatan kaliwungu hidup sehat, salah satu hal yang dilakukan dengan upaya preventif dengan cara pemberian imunisasi dasar lengkap pada anak yang dilakukan di masingmasing posyandu.

Salah satu wujud nyata yang dilakukan di Puskesmas Kaliwungu dalam memberikan pelayanan kesehatan preventif yaitu dengan penyelenggaraan imunisasi. Penyelenggaraan imunisasi di Puskesmas Kaliwungu meliputi perencanaan, pelaksanaan pelayanan imunisasi, monitoring dan evaluasi. Meskipun ada ketidaksesuaian antara peraturan yang mengatur tentang penyelenggaraan imunisasi dasar lengkap dengan realisasi yang diselenggarakan di Puskesmas Kaliwungu, tetapi pada prinsipnya penyelenggaraan imunisasi di Puskesmas Kaliwungu dapat mewujudkan hak kesehatan dan perlindungan anak.

Penyelenggaraan imunisasi di Puskesmas Kaliwungu pada prinsipnya telah dilaksanakan sesuai dengan Permenkes, meskipun ada beberapa hal yang harus diperbaiki. Hal ini dikarenakan terdapat faktor yang mendukung dan faktor yang mengahambat penyelenggaraan imunisasi di Puskesmas Kaliwungu. Adapun faktor pendukung dan faktor penghambat dalam penyelenggaraan imunisasi di Puskesmas Kaliwungu adalah sebagai berikut :

Faktor pendukung

Berdasarkan hasil penelitian di Puskesmas Kaliwungu terdapat faktor pendukung penyelenggaraan imunisasi di Puskesmas Kaliwungu terdiri dari tersedianya kebutuhan logistik dan keamanan menjaga kualitas vaksin. Dalam hal kebutuhan logistik yang terdiri dari vaksin, Auto Disable Stringe dan safety box di Puskesmas Kaliwungu menjadi tanggungjawab Pemerintah melalui Dinas Kesehatan Kabupaten Kudus. Keamanan vaksin merupakan faktor pendukung dalam penyelenggraan imunisasi. Vaksin di Puskesmas Kaliwungu dikelola dengan baik dalam penyimpanannya maupun saat transportas ke posyandu. Keamanan vaksin merupakan salah satu hak pasien dalam pelayanan kesehatan. Hak pasien yang dalam hal ini adalah hak anak untuk diberikan pelayanan kesehatan yang aman. Pengelolaan vaksin yang tepat sampai dengan diberikan kepada anak dapat meningkatkan efektifitas kerja vaksin dalam pencegahan penyakit. Sehingga dapat mewujudkan hak kesehatan anak secara optimal.

Faktor penghambat

Berdasarkan hasil penelitian di Puskesmas Kaliwungu terdapat faktor penghambat dalam penyelenggaraan imunisasi di Puskesmas Kaliwungu. Faktor penghambat adalah faktor sosiologis. Faktor sosiologis yang menjadi penghambat dalam penyelenggaraan imunisasi di Puskesmas Kaliwungu adalah pelaksana pelayanan imunisasi. Hal itu disebabkan karena ketidakseimbangan dalam manajemen penugasan di Puskesmas Kaliwungu. Petugas pelaksana pelayanan imunisasi yang seharusnya dilakukan oleh tiga orang yakni satu orang koordinator imunisasi dan surveilans KIPI, satu orang pelaksana imunisasi, dan satu orang pengelola vaksin. Tetapi di Puskesmas Kaliwungu hanya dilakukan oleh satu orang bidan. Adapun solusi untuk mengatasi faktor penghambat dalam penyelenggaraan imunisasi di Puskesmas Kaliwungu adalah membuat tim petugas pelaksana pelayanan imunisasi. Petugas pelaksana pelayanan imunisasi terdiri dari satu orang koordinator imunisasi dan surveilans KIPI, satu orang petugas pelaksana imunisasi dan satu orang pengelola vaksin dengan didasari surat penugasan dari Puskesmas Kaliwungu.

\section{KESIMPULAN}

Pelaksanaan penyelenggaraan imunisasi belum sesuai dengan ketentuan yang diatur dalam Permenkes, sehingga tugas tersebut dibebankan kepada bidan yang bertugas di poliklinik kesehatan desa. Ketidaksesuaian antara peraturan yang mengatur tentang penyelenggaraan imunisasi dasar lengkap dengan realisasi yang diselenggarakan di Puskesmas Kaliwungu dalam hal petugas pelaksana pelayanan imunisasi, tetapi pada prinsipnya penyelenggaraan imunisasi di Puskesmas Kaliwungu sudah mewujudkan hak kesehatan dan hak perlindungan anak. 
Penyelenggaraan imunisasi dalam mewujudkan hak kesehatan anak di Puskesmas Kaliwungu terdapat beberapa faktor yang mempengaruhi antara lain faktor pendukung dan faktor penghambat.

\section{DAFTAR PUSTAKA}

[1] Eka Arista Prasetyawati, 2012. Kesehatan Ibu dan Anak dalam Millenium Develompment Goals (MDGs), Salemba Medika, Jakarta

[2] Undang-Undang Republik Indonesia Nomor 36 Tahun 2009 tentang Kesehatan

[3] Undang-Undang Republik Indonesia Nomor 39 Tahun 1999 tentang Hak Asasi Manusia

[4] Undang-Undang Republik Indonesia Nomor 35 Tahun 2014 tentang Perlindungan Anak

[5] Peraturan Menteri Kesehatan Nomor 75 Tahun 2014 tentang Puskesmas

[6] Analisis Implementasi Manajemen Program Imunisasi Hepatitis B-0 di Wilayah Kerja Puskesmas Rumbio Jaya Kabupaten Kampar Tahun 2020, JKK (Jurnal Kesehatan Komunitas) KESKOM. 2021;7(1) : 24-32

[7] Peraturan Menteri Kesehatan Nomor 42 Tahun 2013 tentang Penyelenggaraan Imunisasi 